\title{
Digital Divide: Low German and other Minority Languages
}

\author{
Heiko Wiggers \\ Dept. of German and Russian, Wake Forest University, United States of America \\ Email: wiggerh@wfu.edu
}

Doi:10.7575/aiac.alls.v.8n.2p.130

Received: 08/03/2017

URL: http://dx.doi.org/10.7575/aiac.alls.v.8n.2p.130

Accepted: 14/04/2017

\begin{abstract}
This paper investigates the online presence of Low German, a minority language spoken in northern Germany, as well as several other European regional and minority languages. In particular, this article presents the results of two experiments, one involving Wikipedia and one involving Twitter, that assess whether and to which extent minority languages are used on these websites. The article argues that minority and regional languages are not only underrepresented online due to a combination of historical, linguistic, sociological, and demographic reasons, but that the overall architecture of the World Wide Web and its most visited websites is such that smaller languages do not stand a chance to gain a meaningful online presence.
\end{abstract}

Keywords: Low German, endangered languages, minority languages online

\section{Introduction: The Low German Language}

Low German, called Platteutsch by its speakers, was once the dominant language spoken in northern Germany. Its beginnings can be traced back to texts and documents from the $7^{\text {th }}$ and $8^{\text {th }}$ century AD written in Old Saxon (Altsächsisch), the predecessor of modern Low German, although the language is likely much older than that. Linguistically, Low German is a member of the West Germanic language group along with other more well-known languages, such as English, Standard German (Hochdeutsch), and Dutch. Although Low German and Standard German are related, there are considerable differences in lexicon, morphology, and pronunciation. To this day, a conversation between a Low German speaker and a Standard German speaker is near impossible due to the considerable differences between the two languages. By the $14^{\text {th }}$ century, Low German had become a lingua franca in northern Europe, particularly in the Scandinavian countries, due to the power of the Hanseatic League (Hanse), a confederation of merchant guilds that had its centers in the north German cities of Lübeck, Hamburg, and Bremen. Gradually, however, Low German was replaced in northern Germany by Standard German and underwent a massive loss of prestige along with it. The reasons for this were manifold and have frequently been cited in the research literature (Sanders, 1982; Stellmacher, 1990). Chief among them were the emergence of the printing press in Germany, the Reformation, i.e. Martin Luther's preference for High German, the waning power of the Hanseatic League after the $16^{\text {th }}$ century, and perhaps most of all - Low German's perception as a "peasant language". Since the middle of the $20^{\text {th }}$ century, Low German has been experiencing erosion on such a vast scale that in 1998 the European Union added it to its list of Endangered Languages in Europe. Experts (Möller, 2008) estimate that the current number of active Low German speakers in northern Germany is approximately at $1.1-1.2$ million. This number, although it might sound impressive, will barely guarantee a viable future for the language. Indeed, most Low German linguists describe the status of Low German in the $21^{\text {st }}$ century as moribund to a high degree (e.g. Wirrer, 1998).

\section{A Generational Divide}

Perhaps the most significant reason for the dramatic decrease in Low German speakers is self-inflicted, namely the rather widespread reluctance (and inability) of Low German speaking parents to pass the language on to their children. This decision was often propelled by parents' fears that their children would not learn to speak "proper German" if they are raised with Low German as their first language. Indeed, the so-called "Hochdeutschwelle" (High German Wave) of the 1960s and 1970s emphasized the importance of Standard German and even saw several linguists speaking out against the use of dialects in German schools. This was, again, particularly true for Low German; and the result of this development was virtually an entire generation of children in northern Germany who grew up with Standard German only. Tophinke (2015: 126-127) describes the children born in northern Germany in the 1950s and 1960s as "die Kinder der letzten Sprechergeneration" (the children of the last generation of [Low German] speakers). These children, now adults, often still have a certain Low German language competency, while their children, "die Enkel der letzten aktiven Sprecher" (the grandchildren of the last active speakers), usually do not speak Low German at all. In 2014, Tophinke conducted a survey among seventy university students at the northern German University of Paderborn about how much they know about Low German. Tophinke's survey was significant because she did not assume that these students still 
spoke Low German but rather intended to find out what they knew about the language and its speakers. 1 Tophinke's results showed that her subjects often only had a vague idea where Low German is spoken. Tophinke comments that the majority of answers consisted of "ungenaue Antworten, [...], Vermutungen und Schätzungen" (vague answers, assumptions and guesswork, 2015: 128) and summarized her results as follows:

Zwar besitzen die befragten Studierenden noch Wissen über das Plattdeutsche, dieses ist aber vereinfacht und nicht differenziert. [...] Die Antworten lassen nicht erkennen, dass das Niederdeutsche für die Studierenden [...] soziale Alltagsrelevanz besitzt. (2015: 130)2

„It is true that the participants still have some knowledge about Low German, but it is simplified and undifferentiated. [...] The answers of the students do not demonstrate that Low German has any kind of social relevance for their daily lives."

\section{Minority, Regional, and Endangered Languages and the New Media}

Sections one and two have illustrated how Low German has morphed from a majority language in northern Germany to an endangered minority language and the factors contributing to its erosion. A relatively new factor related to the survival of minority, regional, and endangered languages (henceforth called MRE-languages) is their presence or nonpresence on the Internet. Although "Minority Language Media Studies" is developing fast as a new linguistic sub-field (Cormack, 2007) that examines the interrelationship between new media and minority languages, there exists a relatively wide gap of opinions among researchers whether the Internet poses a chance or a danger to minority languages.

The Internet has become ubiquitous in many people's lives. In 2011, the United Nations declared access to the Internet a human right, and expanded this resolution in 2016 by adding that disrupting, restricting, or blocking internet access constitutes a human rights violation. Form the very beginning of the Internet's popularity linguists and sociologists had expressed concerns that English would not only dominate the World Wide Web but would become, in fact, its default language. Fishman, for instance, wrote of a "new linguistic order" that would entail "the total globalization of English" (1999, 26-27). While it is true that by the mid-to late 1990s English made up ca. $80 \%$ of the web's content the fears that it would completely dominate the Interned did not bear out. According to a report by the British paper The Guardian, sponsored by the British Academy, English still is the largest language group online with 800.6 million users, but it is followed closely by Chinese with 649.6 million users.3 In total, the number of users who are non-native English speakers now far outnumber native English-speakers online. A different picture, however, emerges if one is to compute the number of websites by language. As Wright (2006) points out, "reporting in any quantitative way on the state of the W.W.W. is a dangerous enterprise. Even before the research is completed, the situation will have evolved and the data will be inaccurate." (2006, 191). Nonetheless, the American journal The Atlantic reported in 2015 that there existed more than one billion websites on the World Wide Web in 20144. Compared to a mere 3,000 websites online in 1994, this constitutes an increase of thirty-three million percent in just twenty years. Perhaps not surprisingly, the task of assigning more than one billion websites to a specific language is even more cumbersome. Wright (2006) even believes that such an undertaking is "pointless" $(2006,191)$ due to the sheer size of the web, difficulties navigating it, and its ever-changing nature. It seems, though, that websites with English content far outnumber any other language. The German statistics portal statista, for instance, estimates that ca. 53\% of all websites in 2015 were in English. This figure corresponds to the 2013 results of W3Techs, an American-based company for web technology surveys, which put the number of websites with primarily English content at 52.9\%. Such figures, however, need to be treated cautiously given the large number of bilingual and international websites. One could argue that the numerical dominance of websites with English content constitutes a threat to MRE-languages in terms of web presence. In fact, Cormack points out that the web was "not developed with these languages in mind" (2007, 255). However, increased content and particularly increased access has helped many MRE-language communities to receive attention that not only empowers its speakers but may also contribute to the maintenance of the language. Before I discuss whether the extraordinarily fast rise of the Internet as the world's most powerful communication tool is helpful or harmful for MRE-languages, it might be well to first consider the conclusions of the 2005 UNESCO report on "Measuring Linguistic Diversity on the Internet" since it constitutes an account by a neutral, intergovernmental body. The report's authors concede that there exists a "digital divide" $(2005,44)$ among the world's languages online and comment:

"Some languages have large amounts of readily accessible digital content. Internet users, who speak, read, and write such languages have far less difficulty accessing and sharing useful information than speakers of less

1 It is important to point out here that previous surveys about the status of Low German among young adults (Wiggers, 1988; Robben und Robben, 1990; and Kruse, 1992) focused on the subjects' active mastery of Low German (i.e. how well they understand and speak it). The fact that Tophinke abstained from asking the participants of her study about their active knowledge of Low German indicates how much the use of Low German has decreased in the "Enkelgeneration". It is also interesting that the seventy students in Tophinke's survey studied Germanistik, i.e. they were all majoring or minoring in German. Tophinke does not mention the average age of her participants but mentions that they were Studienanfönger (first-year students, freshmen), which would mean that their average age was approximately nineteen or twenty at the time of the survey.

2 Throughout the paper, the translations are mine. (H.W.)

3 German ranks eighth with 81.1 million users

4 The same report also states that the life-span of an average website is ca. 100 days. 
well-represented languages. This situation naturally raises the question of whether the digital information systems, their configurations, or their use constitutes a form of bias against the less well-represented languages." $(2005,44)$.

On the other hand, the authors point out that the Internet by nature encourages complete freedom of language choice:

"The Internet is global and decentralized. No user or group of users can exercise hierarchical control over any other user or group of users, because the Internet allows complete freedom of association. Hence, anyone can use any language, as long as at least one other person is willing to use it as well." $(2005,48)$.

Ultimately, however, the report concludes that "there is a dearth of empirical research that directly addresses these questions of pre-existing, technical, and emergent language bias on the Internet." $(2005,49)$.

\section{Studies Concerning the Online Presence of MRE-Languages}

As of this writing, eleven years have passed since the publication of the UNESCO report which, measured in terms of digital developments, seems almost like an eternity. Since then, quite a few studies and reports have been published that seem to confirm the web's potential to aid MRE- languages in their struggle to survive. Two areas in particular have emerged that appear to be beneficial to speakers of such languages, namely their use of and participation in social networks, and language documentation. The latter one is, of course, not a product of the Internet but has been used by linguists and communities for centuries. However, the Internet with its vast capabilities to store, archive, and disseminate data has given this discipline a new boost. An interesting example are minority languages in Africa, which number more than 1,800 (Batibo, 2009: 196). Batibo (2009) has pointed to the exceptional role that language documentation can play in protecting African MRE-languages:

"Language documentation has been found to be both crucial and central in the preservation, safeguarding, and revitalization of the African languages." $(2009,195)$

Batibo is careful to stress, though, that documentation in and by itself cannot save a language from extinction:

"Just keeping records would mean that we accept their [the languages'] extinction. [...] We need to carry out documentation as another way of empowering and revitalizing the threatened minority languages in Africa." (2009, 196)

A case in point is the Naro Language Project. Naro, spoken by ca. 9,000 people in western Botswana and eastern Namibia, is a member of the Khoisan language family, which is perhaps best known for having click consonants ("click language"). The number of speakers obviously suggests that the language is severely endangered. In the late 1980s and early 1990s, missionaries of the Dutch Reformed Church began the Naro Language Project (NLP), which included the designing of a standard orthography, preparing user-friendly grammars and dictionaries, collecting and compiling literature in Naro for both children and adults, developing reading texts, history books, and newsletters, and translating the Bible into Naro. The NLP began before the advent of the Internet but was later digitalized as well.5 According to Batibo, the NLP has been a great success in terms of empowering Naro speakers and giving the language a new prestige:

"As a result of this type of documentation, which focuses on community and practical use of the primary data, the Naro language and the respective speakers have been highly empowered. This can be evidenced by the fact that the speakers have become more emotionally attached to their language, as they find it as valuable as other languages. This is because it can be written down and that books can be produced for people to read. Thus, the speakers have developed more confidence and higher self-esteem. Moreover, the Naro parents are vigorously encouraging their children to learn the language. The language is now attached to socio-economic gains in terms of literacy and income-generating activities." $(2009,199)$

In fact, this project has been so successful that Naro is now attracting second language speakers.

An example of MRE-language empowerment through use of social media comes to us from Poland, where young, ethnic Kashubians are rediscovering and reconnecting to the Kashubian language of their parents and grandparents via social networks. Kashubian, a West-Slavic language and the only remnant of the old Pomeranian language, is mainly spoken on the southern coast of the Baltic Sea between the Vistula and Oder rivers. Dolowy-Rybinska (2013) reports that there are ca. 500,000 people in Poland left, who identify partly or fully with the Kashubian group. Of these, approximately $60 \%$ can speak the language, but only ca. 80,000 are active Kashubian speakers, i.e. they use it on a daily basis. This is further broken down along generational lines with most speakers belonging to the older generation and almost no younger speakers left. Dolowy-Rybinska points out that only one hundred years ago, every Kashubian was

5 See it current website at: http://www.kuru.co.bw/naro_language_Project.html 
able to speak the Kashubian language.6 After the collapse of communism, Kashubian was recognized as a regional language, and measures were taken to protect and revitalize the language, such as street signs in Kashubian and its inclusion in school curricula. There is a now a sizeable amount of webpages in Kashubian after successful efforts to codify the language. This new online presence has suddenly made it "cool" for younger Kashubians, who do not speak Kashubian, to reacquaint themselves with the language and to use it in online conversations with friends. DolowyRybinska emphasizes that "this is the first time Kashubian has been widely used in such forms [i.e. in writing and online]" $(2013,127)$ and concludes:

"Speaking most broadly, the rise of the Internet has been very advantageous for the Kashubian-speaking community, especially for the young. [...] It [using Kashubian online] has led to an increase in the prestige of the language: if Kashubian can be used online, it cannot be so inferior and unsuitable after all. [....] Young people communicate, exchange remarks Kashubian culture and its function in the modern world, and find other people to whom Kashubian language and culture are also important.

$(2013,127-128)$

An interesting study about the online presence of European MRE-languages was conducted by Wright (2006). The languages surveyed in her team's study were Occitan, Piedmontese, Ladin, Sardinian, and Frisian. Wright reports that

"[...] all five languages in the survey are present on the Internet. Without providing actual figures, which are [...] likely to be misleading and immediately out of date, we can nonetheless report that the Occitan researchers found over a thousand sites, the Sardinian and Frisian researchers hundreds, and the Piedmontese and Ladin researchers dozens. The numbers of websites in which the five languages are used is, therefore, not negligible, and their presence in this medium indisputable." (2006, 192-193).

Wright's primary focus was to find out how much RML (Regional or Minority Language) content is used on RML sites. Although Wright found several significant sites whose content was wholly in the RML, such as news portals in Sardinian (www.sardu.net, and www.comitau.org), the majority of RML content on the Internet was either bilingual (e.g. in Frisian and Dutch), or what Wright termed "symbolic". These are sites that often only contain a fraction of a particular RML. As an example Wright describes the website of the Belgian village Adegem, which contains a welcome message in Frisian alongside other languages, such as Dutch, German, and French. Another symbolic use of RMLs online is to advertise for local products: wineries or olive oil producers will often include a sentence or two in, say, Occitan or Piedmontese to highlight the local character of their products. Although Wright observes that RMLs "have not yet moved into all domains, and there are only mild indications that they will all do so" (2006, 213), she concludes that "the WWW appears to be a medium that will contribute to the preservation and promotion of RMLs" (2006, 213).

All of these developments sound rather encouraging. In fact, in recent years a slew of American media reports appeared, whose headlines alone seem to indicate that internet technology and/or globalization are a cure-all for MRE-languages, such as: "Globalization helps prevent endangered languages" (Yale Global News, December 2013); "For rare languages, social media provide new hope" (NPR, July 2014); and "Technology to the endangered language rescue!" (Huffington Post, January 2015).

However, the relation between MRE-languages and the Internet is much more complex than these press reports seem to conceive it. Indeed, the authors themselves of the above-mentioned case studies remain quite skeptical - in spite of their generally positive findings - whether the Internet can really aid these languages in their struggle to survive in the $21^{\text {st }}$ century. For instance, in her study of Kashubian, Dolowy-Rybinska points out:

"The fact remains that using certain pages in the minority language is unlikely to produce a major linguistic shift among young people; their main language is likely to remain the national language or - in international contacts - English.” (2013, 127).

As for the use of Occitan online, Wright (2006) cautions that the high number of websites with Occitan content amounts at best to "Oc-lite, i.e. a minimal cultural maintenance without going as far as learning or maintaining the language." (2006, 199). Perhaps the most striking aspect of Wright's and Dolowy-Rybinska's studies is the fact that they remain inconclusive, i.e. the authors could not predict whether in the long run the Internet can indeed improve the situation of the languages in question. Interestingly, many other studies on the same subject did come to a negative conclusion, namely that the Internet is no help at all in revitalizing MRE-languages. For instance, the early years of the new millennium saw elaborate efforts to revitalize Niuean, a Polynesian language with ca. 20,000 speakers left, by creating a Niuean cyberspace community and Niuean-only cyber forums. To this end, all Niuenas living on the main island of Niue received free and unlimited access to the Internet. However, after several years of running this experiment, it turned out that only $5 \%$ of Niuean Internet users chose to employ the language online even though the technology to use it online had been considerably facilitated. Sperlich (2005), who had observed the Niuean project from the beginning, believes that "the 5\% margin of "Niuean-only is in the realm of insignificance" (2005:73), and concludes:

6 The reasons for Kashubian's massive and rapid erosion can be found in large flights of Kashubian speakers from the countryside into cities during the $20^{\text {th }}$ century, and, most of all, in forty years of state communism, which banned the use of Kashubian altogether. 
"Cyber forums do not seem to bring about the promised assistance for maintaining and reviving the Niuean language." (2005, 76)

Another case study from 2006, again from Botswana, took into consideration whether the Internet can aid endangered languages as a whole in this country. Mooko, the study's author, believes that "the potential of the Internet to effectively facilitate the promotion of endangered languages" is "questionable" (2006: 122), and cites access and affordability as the main reasons:

"Such technology is most accessible to the affluent and educated members of the society, and no necessarily to the majority of the ordinary people who speak the endangered languages." $(2006,122)$

Access and affordability are indeed two major obstacles that prevent speakers of MRE-languages to achieve an online presence. In 2015, a study by the United Nations' Broadband Commission estimated that ca. three billion people worldwide enjoy regular access to the Internet. That leaves ca. 4.2 billion people, or three-fifths of the global population, with no or irregular Internet access. The vast majority of the three billion people who do have access to the Internet are from developed countries. In 2007, Cunliffe launched an extensive study to investigate the online presence of minority languages and came to the following conclusion:

"The linguistic diversity of the world is poorly reflected on the Internet. [...] $90 \%$ of the world's languages are simply not represented." $(2007,139)$

Similar to Wright, Cunliffe relativizes his observations by adding that part of the problem is obtaining "hard numbers":

"Estimates for online populations of minority language speakers are hard to come by. [...] The figures that are produced for language use online are often commercially motivated, and minority languages typically only represent small markets. Where figures are available, the basis on which they have been estimated is often overly simplistic.” $(2007,138)$

\section{Kornai's 2013 Study}

Although the Internet has considerably progressed since Cunliffe's study the situation of MRE-languages online has paradoxically only gotten worse since then. In 2013, the mathematical linguist Kornai and his team from the Budapest Institute of Technology embarked on a survey of MRE-languages online that is not only the most recent one but is widely seen as one of the most comprehensive and substantial studies completed so far. Kornai's team succeeded in pulling primary data from a host of websites that specialize in collecting and archiving endangered languages, such as Ethnologue, the Open Language Archives Community, Omniglot, and the Crùbadán Project, and in determining a language's online status based on mathematical principles. In addition, Kornai's team was the first to inspect Microsoft and Apple computer products for language support, namely input and OS:

"Input-level support means the availability of some specific method, such a Kotoeri for Japanese, to enter text in the writing system used for the language. Without an input method, digital ascent is impossible, but the converse unfortunately does not hold: the existence of some input method by no means guarantees an easy way to create text in the language, let alone vigorous digital language use. OS-level support means that all interaction conveyed by the operating system, such as text in dropdown menus or error messages, are provided in the language in question." $(2013,4)$.

Kornai's team devised four digital categories: T (Thriving), V (Vital), H (Heritage), and S (Still). The top sixteen thriving languages (English, Japanese, French, German, Spanish, Italian, Portuguese, Dutch, Swedish, Norwegian, Danish, Finnish, Russian, Polish, Chinese, and Korean) were almost identical to the top sixteen Wikipedia languages, and in addition "exactly the languages with OS-support by Apple" (Kornai, 2013: 6). However, at the other end of the spectrum, Kornai estimates that the number of languages with Heritage- or Still-status far exceed "even the most pessimistic survey" (2013: 10). In fact, based on his team's calculations Kornai predicts that less than three hundred languages will have an online presence by the $21^{\text {st }}$ century:

"With only 250 digital survivors, all others must inevitably drift towards digital heritage status or digital extinction. [...] There could be another 20 spoken languages [...] that may make it, but every one of these will be an uphill battle. For $95 \%$ of the world's languages there is very little hope of crossing the digital divide." $(2013,10)$

Furthermore, Kornai points out that it is very difficult for MRE-languages to secure digital ascent, i.e. achieving and maintaining an online presence, while digital descent, i.e. either never achieving an online presence in the first place or slipping into digital obscurity is quite common for these languages. According to Kornai, digital descent frequently ends in digital death, which is largely irreversible: 
"We emphasize that this massive die-off is not some future event that could, by some clever politics, be avoided or significantly mitigated - the deed is already done." $(2013,7)$

\section{Low German: Websites and Links}

The only comprehensive study of Low German online so far was conducted by Reershemius in 2015 . Reershemius mainly examined one of the largest portals for Low German, Plattnet, and studied various Facebook groups dedicated to speaking and preserving Low German. In addition to re-analyzing Plattnet, this study is also taking into account Low German media content offered by the radio station NDR (Norddeutscher Rundfunk = North German Broadcasting Service), the Institut für Niederdeutsche Sprache (Institute for Low German Language), and the presence of Low German on the online encyclopedia Wikipedia. Section five will discuss the findings of my study, the amount of Low German used on the social network Twitter.

Plattnet, founded privately in 2000, is the largest website portal for Low German and was analyzed twice by Reershemius, in 2009 and 2014 respectively. The website is bilingual, i.e. it posts articles and links in Standard German and Low German. Reershemius describes Plattnet as having a

schlichten Auftritt im Hinblick auf mulimodale Präsentation: Es enthält keine Bilder, Grafiken oder Videos. Der Auftritt von Plattnet hat sich zwischen den beiden Beobachtungsphasen, also zwischen 2009 und 2014, nicht verändert. $(2015,60)$

„a simple appearance with respect to multimodal presentation: it does not contain any pictures, graphics, or videos. The appearance of Plattnet did not change between the two observation phases, i.e. between 2009 and 2014."

Plattnet's appearance is still the same in January 2017, when it was examined again for the present study. The simple layout may be due to the fact that the portal is maintained by a single person. The website has a guide ("Wegbeweiser") in Standard German that directs users to a variety of topics, such as church, literature, events, news, music, etc. Similar to Wright's study (see section four), the links and activities listed under each topic are sometimes monolingual (i.e. in Low German only), or bilingual (Standard German and Low German), or symbolic (i.e. only a fraction is in Low German or Low German is merely referenced). A very good example of a monolingual link is www.diesel-online.de, a news journal in Low German for the coastal region of Ostfriesland. The overall majority of links on Plattnet, however, are bilingual; and quite a few, especially in the "events section" only reference Low German, e.g. musicians or groups who have one or two Low German songs in their repertoires. Several of Plattnet's links are not updated. For instance, the website www.predigten-online.de is described as "Plattdüütsche Predigten" (Low German church sermons). However, the link leads users to a webpage that is entirely in Standard German without any references to Low German. Non-updated and broken links were already a problem when Reershemius analyzed Plattnet in 2009 and 2014 (2015, 60). Reershemius reports that the number of links had grown from 529 in 2009 to 570 in 2014 but thinks that the actual number was considerably lower due to links that were broken, expired, doubled, or not updated. The number of links on Plattnet in January 2017 is 520, which amounts to nine links less than in 2009 and fifty links less than in 2014. In fact, it is very likely that the actual number of links in January 2017 is under 500 if one subtracts broken and not updated links. The reason(s) for the numerical decline of links between 2014 and 2017 is not clear. Maintenance issues, less interest in visiting the portal, or less interest in the Low German language in general are all conceivable reasons but must ultimately remain speculative at this point. On the whole, however, Plattnet may still be considered one of the foremost platforms for Low German in terms of individual effort and commitment to maintaining an online presence for the language.

The websites by the NDR and by the Institut für Niederdeutsche Sprache may be regarded as the two leading platforms in terms of institutional support. The Norddeutscher Rundfunk (NDR), founded in 1956, is a public radio and television broadcaster that has its main seat in the city of Hamburg. In addition to Hamburg, the NDR transmits its programs (originally only radio broadcasts) all over northern Germany, i.e. for the German states of Niedersachsen (Lower Saxony), Schleswig-Holstein, and Mecklenburg-Vorpommern. The NDR is funded by viewers and listeners ("license fees"), tax payer money, and through contributions by the above-mentioned four federal states. As the premier broadcasting station for northern Germany, the NDR has had traditionally a strong commitment to Low German since many of its listeners and viewers speak and understand the language. The NDR's website www.ndr.de includes a significant list of radio and television programs in Low German that were produced by the NDR, such as news, radio plays, daily sermons, podcasts, several television shows in magazine-style format, and even sitcoms. Internet users can click on many of the links provided on the website and view or listen instantly to the program. The appearance of the NDR's website is very professional and similar to that of other news broadcasters, such as the United States' cnn.com or Germany's spiegel.de.

The Institut für Niederdeutsche Sprache (INS) is a scholarly institution, founded in 1973/74 with seat in the city of Bremen, whose goal is the preservation and promotion of the Low German language. The INS is funded mainly with state money by the federal states of Bremen, Hamburg, Schleswig-Holstein, and Niedersachsen. Among the INS' many fields of activities are projects with local schools, kindergartens, authors, theater groups, musicians, churches, and others. In addition, the INS works closely with several universities in northern Germany (Flensburg, Kiel, Münster, Göttingen, Hamburg, and Bielefeld), that house "Departments for Low German" (Niederdeutsche Abteilung) to foster scientific research on Low German. The Institute's website www.ins-bremen.de is bilingual (German and Low 
German) and emphasizes mainly scholarly contributions, such as articles and dictionaries. In addition, it posts numerous links to cultural and academic events. The websites' appearance is quite professional, and it maintains a meticulously up-to-date status.

\section{Low German and other MRE-Languages on Wikipedia}

There are probably few websites that are as representative of the information age as the collaborative online encyclopedia Wikipedia. The free online encyclopedia is by now the sixth most-visited website in the world. To be included on Wikipedia is a significant achievement for a MRE-language and can hardly be overestimated, as Kornai points out:

"The need for creating a Wikipedia is quite keenly felt in all digitally ascending languages. [...] Experience shows that Wikipedia is always among the very first active digital language communities, and can be safely used as an early indicator of some language crossing the digital divide. To summarize: No Wikipedia, no ascent. [Italics by Kornai]. $(2013,3)$

The "Wikipedia-Status" of a language is determined by several factors, such as number of articles, administrators, edits per article, and active users (i.e. Wikipedia users who have made at least one edit in the last thirty days). Perhaps not surprisingly, Wikipedia itself provides a detailed list of a language's status that is updated daily (at: https://meta.wikimedia.org/wiki/List_of_Wikipedias). There are presently 293 languages represented on Wikipedia; and Low German occupies position number 100 on this list with 25754 articles, 4 administrators, and 52 active users. As expected, English was ranked at number one with 5322640 articles, 1.273 administrators, and 119453 active users. German was ranked at number four with 2016254 articles but ranked second in terms of administrators (198) and active users (17 819). There were thirteen languages that had generated more than one million Wikipedia articles, and of those ten are among the top sixteen thriving languages mentioned by Kornai. It would be futile to compare the Wikipedia-Status of Low German to these languages; and it seems rather more constructive to compare it to other MRE-languages mentioned in this article.

Table 1. The Wikipedia-Status of Low German, Occitan, Piedmontese, Sardinian, and Kashubian (January 2017)

\begin{tabular}{ccccc}
\hline Language & $\begin{array}{c}\text { Rank on } \\
\text { Wikipedia by } \\
\text { Number of } \\
\text { articles }\end{array}$ & $\begin{array}{c}\text { Number of } \\
\text { Articles }\end{array}$ & $\begin{array}{c}\text { Number of } \\
\text { Administrators }\end{array}$ & $\begin{array}{c}\text { Number of } \\
\text { Active Users }\end{array}$ \\
\hline Occitan & 63 & 82436 & 4 & 92 \\
\hline Piedmontese & 71 & 63994 & 9 & 34 \\
\hline Low German & 100 & 25754 & 4 & 13 \\
\hline Kashubian & 162 & 5.275 & 1 & 21 \\
\hline Sardinian & 164 & 5.237 & 2 & 53 \\
\hline
\end{tabular}

Ladin, researched by Wright, had no Wikipedia articles.7 Table one demonstrates that most of the MRE-languages mentioned in this article, including Low German, have achieved "Wikipedia-Status". This in itself may be seen as quite a feat considering that approximately 5,500 - 5,700 of the world's languages are absent from Wikipedia; i.e. there were zero Wikipedia articles available in these languages as of January 2017. In the case of Ladin, for example, this means that Wikipedia has an entry about the Ladin language (at: https://en.wikipedia.org/wiki/Ladin_language) but no articles in Ladin. In addition, 97 of the 293 languages listed had fewer than 3.000 articles. Among those, 45 had less than 1.000; many of them Native American languages, such as Cree (125 articles), Choctaw (6 articles), or Muscogee (1 article).

Although the number of articles for the MRE-languages in table one look for the most part solid and perhaps even impressive, they are by no means a strong indicator whether these languages can be really regarded as digitally ascending, as Kornai maintains. To this date, there are no studies that investigate the actual presence of a particular language on Wikipedia. The number of administrators and active users seem to indicate that a dedicated, small group of speakers/users (less than 100 for each language) are mostly responsible for maintaining an MRE language's Wikipedia presence. Compared to the top ten languages, these numbers seem rather negligible. Kornai assumes that a language's mere presence on Wikipedia seems to be sufficient to gain and secure digital ascent. This paper, however, argues that a presence on Wikipedia, even with a sizeable amount of articles, is no safeguard to really assure digital ascent. Other factors, such as article length, and particularly depth, availability and adequacy of information, are equally important for a meaningful online presence.

In order to investigate the actual Wikipedia presence of some of the MRE-languages mentioned in this paper, I examined the size and availability of Wikipedia articles in Low German, Occitan, Kashubian, and Piedmontese by launching a Wikipedia search for fifteen common terms in each language and conducting a word count for each entry (if

7 Friulian, spoken in northern Italy and like Ladin a member of the Rhaeto-Romance language family, was ranked at 191, with 3,157 articles, 1 administrator, and 18 active users. 
applicable). This study took place between November 2016 and January 2017. References were not included in the word count. Terms that could be associated with a language, for example Hamburg with Low German, Mediterranean Sea with Occitan, etc., were avoided. Standard German and Standard English served as reference languages. The results are shown in tables two to four:

Table 2. Wikipedia Articles by Number of Words I (January 2017)

\begin{tabular}{lccccc}
\hline \multicolumn{1}{c}{ Language } & "Barcelona" & $\begin{array}{c}\text { Terms } \\
\text { "Alexander } \\
\text { the Great" }\end{array}$ & "Moon" & "Milk" & "Knife" \\
\hline English & 9.817 & 12310 & 11101 & 11600 & 4.833 \\
\hline German & 6.203 & 16858 & 12794 & 3.901 & 6.373 \\
\hline Occitan & 1.054 & 1.363 & 3.845 & 2.219 & 205 \\
\hline Low German & 314 & 260 & 426 & 94 & No Entry \\
\hline Kashubian & 319 & No Entry & 70 & 111 & No Entry \\
\hline Piedmontese & 457 & 134 & 375 & No Entry & No Entry \\
\hline
\end{tabular}

Table 3. Wikipedia Articles by Number of Words II (January 2017)

\begin{tabular}{|c|c|c|c|c|c|}
\hline \multirow[t]{2}{*}{ Language } & \multicolumn{5}{|c|}{ Terms } \\
\hline & "Plastic" & "Tennis" & "Equator" & "Japan" & "Gold" \\
\hline English & 6.067 & 10119 & 2.371 & 12915 & 10647 \\
\hline German & 9.362 & 5.429 & 1.145 & 11688 & 9.749 \\
\hline Occitan & 23 & 2.639 & 1.265 & 7.378 & 409 \\
\hline Low German & No Entry & 3.943 & 146 & 139 & 5.133 \\
\hline Kashubian & No Entry & No Entry & No Entry & 423 & 159 \\
\hline Piedmontese & No Entry & No Entry & No Entry & 209 & 44 \\
\hline
\end{tabular}

Table 4. Wikipedia Articles by Number of Words III (January 2017)

\begin{tabular}{lccccc}
\hline \multicolumn{1}{c}{ Language } & "Mathematics" & "Carrot" & $\begin{array}{c}\text { Terms } \\
\text { Culius }\end{array}$ & "Eagle" & "Magnet" \\
\hline English & 5.172 & 3.714 & 8.847 & 2.953 & 6.133 \\
\hline German & 3.713 & 2.152 & 7.793 & 729 & 1.341 \\
\hline Occitan & 3.808 & No Entry & 3.477 & 699 & 109 \\
\hline Low German & 309 & No Entry & 450 & 181 & No Entry \\
\hline Kashubian & 38 & No Entry & No Entry & No Entry & No Entry \\
\hline Piedmontese & 4,797 & No Entry & 64 & No Entry & No Entry \\
\hline
\end{tabular}

These tables illustrate that a small Wikipedia crew (15-60 administrators and active users) often results in very short articles and/or no articles at all. In fact, the low word counts for most of the MRE-language articles seem to indicate that many of them were not the result of collaboration but the work of a single author. It should be pointed out that this study included other common terms and names which did not yield any results in Kashubian, Low German, and Piedmontese, among them "frog", "pyramid", "snow", "birthday", "mobile phone", "Louis Pasteur", and "Mikhail Gorbachev". In addition, the four MRE-languages hardly ever listed any references for their articles nor any further links for more information on the respective topics. As a comparison, the entry "Barcelona" had one hundred and thirtyfive references on the English page, twenty-five on the German page, and zero references in Occitan, Low German, Kashubian, and Piedmontese. This is most-likely due to the fact that there are no references in Low German or Kashubian about Barcelona on the Internet. A check of the Low German results in this study shows that its average word count per article is somewhat higher than Kashubian and Piedmontese, whose presence on Wikipedia seems rather precarious. In several cases, however, the word count and depth of information for the MRE-languages was not subpar: for instance, the entries "tennis" and "gold" for Low German, and "Mathematics" for Piedmontese yielded results that either almost matched or even outnumbered those for German and English. The reason is not quite clear. It is possible that these articles were the results of collaboration rather than a contribution by a single active user. 
The results of this short study should be seen as addendum to Kornai's assumption that elevating a MRE-language to "Wikipedia-Status" assures digital ascent. The brevity of many of the articles and the paucity of information may cause more problems than benefits, such as perceptions that these languages are unrefined, unsophisticated, and second-rate. The voluntary work of the respective Wikipedia crews can, of course, not be faulted for this dilemma. Rather, these numbers underscore the fact that languages with fewer speakers do not have a good or even fair chance of succeeding on Wikipedia, which in turn negatively impacts a meaningful online presence. The results furthermore seem to indicate that in spite of more than 25,000 entries Low German's presence on Wikipedia seems relatively unstable based on word count as well as depth and availability of information. This conclusion, however, must be considered preliminary, and a study larger in scope will be needed to genuinely validate it.

\section{Low German on Twitter}

Even surpassing Wikipedia's popularity are social networks, such as Facebook, Instagram, and Twitter. Once again, some figures, culled from the Hamburg-based statistics portal statista, and the U.S. Pew Research Center, will be helpful in illustrating the enormous significance of social networks in the $21^{\text {st }}$ century. Currently, the number of active social network users world-wide amounts to 2.34 billion. According to statista, this number is expected to rise to 2.95 billion in 2020, i.e. approximately one-third of the earth's population. Facebook is by far the most popular social network with ca. 1.712 billion users worldwide, followed by WhatsApp with one billion users. Twitter occupies number nine with 317 million users.8 According to the Pew Research Center, the popularity of social networks in the U.S. is such that they are in the process of replacing traditional news outlets. For instance, $62 \%$ of U.S. adults (i.e. six in ten Americans) now get their news on social media, which included coverage of the 2016 presidential elections. 9 Since the most popular social networks were largely founded by U.S. entrepreneurs it is perhaps no surprise that the most popular user language is English. Although numbers for Facebook are hard to come by due to the large number of multilingual users, it must be estimated that well over 50\% of all Facebook members use English in some form when on Facebook. The language distribution on Twitter is somewhat more diversified. Similar to other social media, English is used the most; however, the percentage of English "tweets" is relatively low at 34\%. This is followed by Japanese with $16 \%$, Spanish with $12 \%$, Malay with $8 \%$, at Portuguese and Arabic with $6 \%$ each.

One of the most effective ways to measure the popularity of social networks is the so-called "Social Network Penetration"- Index, i.e. the amount of current use or adoption of social networks compared to the total theoretical market for them in a specific country.

Table 5. Active Social Network Penetration by Selected Countries (2016)

\begin{tabular}{cc}
\hline Country & Percentage of Social Network Penetration \\
\hline South Korea & $76 \%$ \\
\hline Hong Kong & $66 \%$ \\
\hline Argentina & $62 \%$ \\
\hline USA & $59 \%$ \\
\hline United Kingdom & $59 \%$ \\
\hline Canada & $58 \%$ \\
\hline Japan & $42 \%$ \\
\hline Germany & $36 \%$ \\
\hline Indonesia & $30 \%$ \\
\hline
\end{tabular}

Table five illustrates that the German market for social networks is far from being saturated. This is particularly true for German Twitter accounts. According to the British paper The Economist, Germany, with a population of ca. 82 million, had approximately four million Twitter accounts in 2013 and ranked $31^{\text {st }}$ world-wide in terms of public tweets. The German language does not appear among the top ten languages used on Twitter. Although these figures seem low for a technologically advanced country like Germany, they still translate into 59 million tweets sent in 2013. By 2016, according to figures released by Twitter itself, ca. 12 million Germans used Twitter monthly. This figure, however, is composed of Twitter members with an account and non-members who read tweets without being logged in.10 These numbers seem to indicate that Twitter accounts have increased in Germany since 2013, and that, consequently, the number of public tweets in 2016 was upward of 60 million. In order to find out if and to what extent Low German is used by German Twitter users I conducted the following experiment.

\subsection{Experiment Description}

Twitter provides an API or Automatic Programming Interface which allows users to register for free for a Twitter Developer account and then access a small percentage of Tweets directly from their databases instead of the standard user interface on the web. The information available through the Twitter API contains the tweet text itself along with a

8 Source: statista, https://www.statista.com/statistics/272014/global-social-networks-ranked-by-number-of-users/ 9 Source: http://www.journalism.org/2016/05/26/news-use-across-social-media-platforms-2016/

10 Source: http://www.zeit.de/digital/2016-03/soziale-medien-twitter-nutzerzahlen-deutschland 
large number of metadata fields including the latitude and longitude of the tweet if the geolocation setting is active on the user device. In this study the programming language R (R Core Team, 2016) was used to interface the Twitter API and to collect random tweets with latitude and longitude coordinates located within a geo-coordinate bounding box that included northern Germany and parts of southern Denmark. Data collection spanned over an eight-day period in which random live tweets were captured for an hour every two hours during the 24 hour period of a day.

8.2 Results

Altogether 3.366 Tweets were captured between September 12, 2017 and September 20, 2017. Of these, approximately $75 \%$ were written in German, and ca. 24\% in English. Roughly 1\% was in Turkish. Not one single tweet was composed in Low German. Twenty-two tweets $(=0.0065 \%)$ had one Low German word in them; however, no tweet was detected that contained more than one word in Low German. The most used Low German word was the greeting moin (="hello/good day") which appeared in fourteen tweets. These fourteen tweets, though, came from four individual members, which reduces the number of Twitter users, who use at least one Low German word, even further. In addition, this greeting, although of Low German or Frisian origin, has become so ubiquitous in northern Germany that one can hardly draw conclusions about the Low German language competency of its users. The total results of Low German words are in table six:

Table 6. Use of Low German on Twitter (September 11 - September 20, 2016)

\begin{tabular}{lll}
\hline Low German Word & Meaning & Frequency in Tweets \\
\hline moin & Hello/Good Day & $14 \mathrm{x}$ \\
\hline waterkant & coast & $4 \mathrm{x}$ \\
\hline gedöns & things/stuff & $2 \mathrm{x}$ \\
\hline schnacken & to speak & $1 \mathrm{x}$ \\
\hline schippern & to sail & $1 \mathrm{x}$ \\
\hline buddel & bottle & $1 \mathrm{x}$ \\
\hline
\end{tabular}

Statistically speaking, the results for Low German are effectively insignificant and suggest that the language is not used at all on Twitter.

8.3 Interpretation of Results and Conclusion

This paper argues that the quasi non-existence of Low German on Twitter is not only due to its endangered status but rather a combination of factors that go somewhat beyond the domain of purely linguistic reasons.

a) Regionality and orthography

Low German is not and never has been a homogenous language but rather a progression of related dialects. . In some cases, a mere distance of thirty kilometers can result in quite different lexical terms and expressions. A Low German speaker from Hamburg would have little to no problem to communicate with a speaker from, say, Stralsund, but Low German's lack of standardization would likely be seen as a deterrent to use the language on social media such as Twitter. This is particularly true for matters of spelling. In the $20^{\text {th }}$ century, many Low German varieties have established their own orthography, but these are not taught in school and most speakers are unaware of them. In fact, one result of Low German's long and slow erosion is a large number of speakers who are uncertain how to spell their language. This is not to say that regional languages are incompatible with Twitter. A study from the Netherlands showed that Frisian, a regional language closely related to Low German, is used quite actively on Twitter.11 Low German speakers, however, tend to use Standard German if they use social media at all. In addition, Low German's regional character seems rather incongruous with social media, which largely came into existence to make long-distance communication easier. For instance, the speakers of a language variety that is limited to a thirty kilometer radius would most-likely rather meet in person or speak on the phone than sending tweets to each other.

b) Skepticism toward and rejection of social media

Germans are among the least enthusiastic social media users in the world. A survey conducted by the Pew Research Center ranks Germany alongside Pakistan with ca. 50\% social media users, i.e. one half of all Germans who use the Internet do not use social media. The study furthermore says that in general internet users with at least some college experience have been consistently more likely to use social media over the past decade than those with less education. Germany, however, is the only country in the western world where higher education levels are associated with significantly less social media use. The reasons for this skepticism are likely to be found in Germany's troubled past: the privacy abuses of the Third Reich and later in communist East Germany left many Germans more protective of their privacy, online and otherwise, than in most western countries. This is particularly true for Twitter where users reveal their location when sending out tweets.

c) Demographics and Internet use

The low number of social media users may be explained by Germany's demographics. Germany is an aging society with a declining birth rate. The Pew study found that only $39 \%$ of German Internet users over thirty-five use social media, and even less in the group over fifty-five. It is possible that the excesses of the Nazis and Communists linger on

11 For more information, see Cornips, Nguyen, and Trieschnigg (2015) 
more vividly in the minds of German seniors and that they therefore shun social media in general. For Low German, however, this trend is very detrimental since the majority of speakers belong to the older generation as shown in section two.

d) The orality of Low German and appropriateness

Technically, any language can be tweeted as long as the appropriate script is provided on Twitter. However, smaller and regional languages like Low German are often embedded in a profound oral tradition. A new electronic format that restricts communication to 140 characters simply seems incompatible with the way the language is typically used. Nothing could illustrate this better than the much-cherished "klön" or "schnack", chats held in Low German during informal get-togethers and (frequently drawn-out) personal visits. In other words, many Low German speakers will likely consider Twitter to be a medium for quasi-anonymous, solitary, and extremely abbreviated discourse that could never replace or even come close to the joy and importance of daily face-to-face conversations. Similarly, it would seem out of character and even somewhat inappropriate to send out tweets in Low German, such as "I am taking my dog for a walk", or "I am doing my laundry right now."

The above-mentioned arguments all add up to one final point: Low German has no or very few digital natives. This term, fist coined by Prensky in 2010, usually refers to people who were born into the digital computer age, possess the skills and are eager to use new technologies, and are able to afford them. It is clear that a language needs many digital natives in order to establish and secure a meaningful online presence. Low German is certainly not the only MRElanguage with few digital natives. The fact that the overall majority of the world's languages are not represented online seems to imply that this is not a regional but a universal problem. It is difficult to locate reasons why this is the case. After all, as Perlin (2014) points out, the Internet was created with equality in mind:

"The digital realm was supposed to be different - a horizontal platform, a great equalizer that would allow everyone to communicate seamlessly with one another. What went wrong?" $(2014,2)$

It is interesting to note that the Internet was and is instrumental in achieving more equality for many subcultures and for previously marginalized groups. Moreover, the Internet, and particularly social media, have become a powerful tool for the politically and religiously oppressed, and for those who otherwise have no voice. In this respect, current buzzwords such as "connectivity" and "empowerment" really are more than just phrases. The problem is that these terms do not extend to most MRE-languages. Internet access and affordability remain real issues but can usually be fixed if governments and tech companies are willing to invest. However, with a few exceptions, the Internet has given no voice to the many speakers of MRE-languages around the world. Blogs in Basque, smart phone apps in Cherokee, etc. are tremendous accomplishments by language activists. But their faith that such digital tools can help these languages achieve a lasting online presence is misplaced. Or, as Kornai puts it:

"Heritage projects are haphazard [and] resources are squandered on feel-good revitalization efforts that make no sense in the light of the preexisting functional loss and economic incentives that work against language diversity $[\ldots]$. For the overwhelming majority of languages, the glorious digital tomorrow will never arrive." $(2013,10)$

The final question to address is in which digital category Low German needs to be placed. Kornai's four categories, Thriving, Vital, Heritage, and Still, do not seem entirely suitable. Low German's online presence is certainly not thriving nor is it vital or completely still. This would leave "Heritage", which is defined by Kornai as

"languages that are digitally archived but not used for communication by native speakers. Their digital presence is read only, and maintained by scholars." $(2013,3)$

Low German's strong support by state governments and public broadcasters suggests that the language is not yet in the heritage-category. In addition, Low German is frequently used for daily communication; but this communication is, for the most part, happening offline.12 Low German's current digital status might best be described as "significantly less than vital but somewhat more than heritage." The language will perhaps be able to maintain this in-between status as long as (north) German officials, broadcasters, and universities continue to support it. However, with ever-decreasing numbers of active speakers and no new digital natives emerging, it seems likely that eventually Low German, like so many other MRE-languages, will be banished to a digital heritage status.

\section{References}

Batibo, H. M. (2009). Language Documentation as a Strategy for the Empowerment of the Minority Languages of Africa. Selected Proceedings of the $38^{\text {th }}$ Annual Conference on African Linguistics, 193-203.

Cormack, M. \& Hourigan, N. (2007). Minority Language Media. Concepts, Critiques and Case Studies. Bristol: Multilingual Matters.

12 Reershemius reports that Low German or a mixture of Low and High German is used on several small Facebook groups (2013: 63-75). However, the present status of these groups is unknown. 
Cornips, L. \& Nguyen, D \& Trieschnigg, D. (2015). Audience and the Use of Minority Languages on Twitter. Proceedings of the Ninth International AAAI Conference on Web and Social Media, 666-669.

Cunliffe, D. (2007). Minority languages and the internet: new threats, new opportunities. In Mike Cormack \& Niamh Hourigan (Eds.) Minority Language Media: Concepts, Critiques, and Case Studies (pp.133-150). Bristol: Multilingual Matters.

Dolowy-Rybinska, N. (2013). Kashubian and Modern Media: The Influence of new Technologies on Endangered Languages. In Elin Haf Gruffyyd Jones \& Enrique Uribe-Jongbloed (Eds.) Social Media and Minority Languages: Convergence and the Creative Industries (pp. 119-130). Bristol: Multilingual Matters.

Emmanoulido, L. (2014). For Rare Languages, Social Media Provide New Hope. [online, NPR]. Available: http://www.npr.org/sections/alltechconsidered/2014/07/26/333732206/for-rare-languages-social-media-provide-newhope (February 15, 2017).

Fishman, J. (1999). The new linguistic world order. Foreign Policy 113(1), 26-40.

Gottfried, J. \& Shearer, E. (2016). News Use across Social Media Platforms 2016. [online, Pew Research Center]. Available: http://www.journalism.org/2016/05/26/news-use-across-social-media-platforms-2016/ (February 15, 2017).

Greenwood, S. \& Perrin, A. \& Duggan, M. (2016). Social Media Update 2016. [online, Pew Research Center]. Available: http://www.pewinternet.org/2016/11/11/social-media-update-2016/ (February 15, 2017).

Kornai, A. (2013). Digital Language Death. PLOS ONE 8(10), 1-11.

Kruse, A. (1993). Zur Lage des Plattdeutschen im nordwestlichen Ostfriesland. Ergebnisse einer Befragung von Schülern und Schülerinnen aus Emden und Umgebung. Quickborn 86, 64-83.

Lafrance, A. (2015). How many websites are there? [online, The Atlantic] Available: https://www.theatlantic.com/technology/archive/2015/09/how-many-websites-are-there/408151/ (February 15, 2017)

Mooko, T. (2006). Counteracting the Threat of Language Death: The case of minority languages in Botswana. Journal of Multilingual and Multicultural Development 27(2), 109-125.

Möller, F. (2008). Plattdeutsch im 21. Jahrhundert. Bremen: Verlag Schuster Leer.

Paolillo, J. \& Pimienta, D. \& Prado, D. (2005). Measuring Linguistic Diversity on the Internet. United Nations Scientific, Educational and Cultural Organization.

Perlin, R. (2014). The Internet, where languages go to die? [Online, Al-Jazeera America] Available:http://america.aljazeera.com/opinions/2014/3/languagelinguisticstechnologyinternetdigitaldivideicann.html

(February 15, 2017).

Prensky, M. (2001). Digital Natives, Digital Immigrants. On the Horizon 9(5), 1-6.

Reershemius, G. (2015). Kleinere, regionale und Minderheitssprachen im Web 2.0 am Beispiel des Niederdeutschen. In Elin Fredsted \& Robert Langhanke \& Astrid Westergaard (Eds.), Modernisierung in kleinen und regionalen Sprachen (pp. 53-83). Hildesheim: Georg Olms Verlag.

Robben B. \& Robben A. (1993). Mundartgebrauch im Kreis Emsland: eine regionale Schüler- und Elternbefragung. In Ludger Kremer (Ed.), Diglossiestudien: Dialekt und Standardsprache im niederländisch-deutschen Grenzland. (pp. 89122). Vreden: Landeskundliches Institut Westmünsterland.

Sanders, W. (1982). Sachsensprache, Hansesprache, Plattdeutsch. Göttingen: Vandenhoeck \& Ruprecht.

Sperlich, W.B. (2005). Will cyberforums save endangered languages? A Niuean case study. International Journal of the Sociology of Language 172, 51-77.

Stellmacher, D. (1990). Niederdeutsche Sprache - eine Einführung. Bern: Lang Verlag

Stern, A. (2016). Technology to the Endangered Language Rescue! [online, The Huffington Post]. Available: http://www.huffingtonpost.com/alissa-stern/technology-to-the-endange_b_6225900.html (February 15, 2017).

Tophinke, D. (2015). Spurensuche - Zur Gegenwart des Niederdeutschen im ostwestfälischen Raum. Jahrbuch des Vereins für niederdeutsche Sprachforschung 138, 119-145.

Wiggers, R.K. (1988). Zum Stand des Plattdeutschen bei Oldenburger Schülerinnen und Schülern. Quickborn, 78, 1518.

Wirrer, J. (1998). Zum Status des Niederdeutschen. Zeitschrift für Germanistische Linguistik 26 (3), 309-340.

Wright, S. (2006Wright, Sue (2006). Regional or Minority Languages on the WWW. Journal of Language and Politics, 5(2), $189-216$.

\section{Web Articles}

Why do Germans shun Twitter? (December 18, 2013). [online, The Economist]. Available: http://www.economist.com/blogs/babbage/2013/12/social-media (February 15, 2017).

Global social network penetration rate as of January 2016, by region. [online, statista]. Available: https://www.statista.com/statistics/269615/social-network-penetration-by-region/ (February 15, 2017). 


Leading social networks worldwide as of January 2017. [online, statista]. Available:
https://www.statista.com/statistics/272014/global-social-networks-ranked-by-number-of-users/ (February 15, 2017).

Twitter nennt erstmals Nutzerzahlen für Deutschland (March 21, 2016). [online, Die Zeit]. Available: http://www.zeit.de/digital/2016-03/soziale-medien-twitter-nutzerzahlen-deutschland (February 15, 2017).

Educated Germans avoid social media (November 25, 2015). [online, Deutsche Welle]. Available: http://www.dw.com/en/educated-germans-avoid-social-media/a-18875970 (February 15, 2017).

Globalization helps prevent endangered languages (2013). [online, Yale Global Online]. Available: http://yaleglobal.yale.edu/content/globalization-helps-preserve-endangered-languages (February 15, 2017).

Die Deutschen sind die Facebook-Muffel der Welt (February 22, 2016). [online, Die Welt]. Available: https://www.welt.de/wirtschaft/webwelt/article152520908/Die-Deutschen-sind-die-Facebook-Muffel-der-Welt.html (February 15, 2017). 